\title{
Unexpected angiographic and visual findings after clipping of a carotid-ophthalmic aneurysm
}

\author{
L. Mascarenhas; M. Ribeiro*; S. Guimaraes**; J. Rocha* and C. Alegria \\ Neurosurgery, ${ }^{*}$ Neuroradiology and **Ophthalmology Services . São Marcos Hospital. Braga. Portugal.
}

\section{Summary}

A 56-year-old woman underwent surgery for a ruptured carotid-ophthalmic artery aneurysm. Intraoperative visual inspection confirmed that the ophthalmic artery was left intact. She had no light perception on the operated side right after surgery. Angiography one week after surgery confirmed exclusion of the aneurysm, no filling of the proximal portion of the ophthalmic artery, and a very faint filling of its distal orbital part. She gradually recovered from this deficit and 9 months after surgery she is capable of counting fingers. At this time angiography displayed filling of all the portions of the ophthalmic artery, absence of recruitment of collateral blood supply, and exclusion of the aneurysm as before. Surgical manipulation seems to either have induced vasospasm or thrombosis of the ophthalmic artery. Regression of vasospasm or secondary recanalization of the thrombus without development of collateral blood supply may account for the gradual improvement of vision. A risk of monocular blindness is associated with the surgical treatment of para-clinoid aneurysms. Nevertheless, when it occurs, a perspective of recovery may exist if certain etiologies are involved.

KEY WORDS: Ophthalmic artery. Aneurysm. Surgery. Angiography. Transitory visual deficit

Hallazgos angiograficos y visuales inesperados tras clipage de aneurisma carotido-oftálmico

\section{Resumen}

Una mujer de 56 años fue intervenida de un aneurisma carotido-oftálmico roto. La inspección visual intraoperatoria confirmaba que la arteria oftálmica estaba intacta. Tras la cirugía la paciente no percibía luz por dicho ojo y la angiografía una semana después de la cirugía confirmó la exclusión del aneurisma, con falta de

Recibido: 23-03-09. Aceptado: 15-08-09 relleno de la porción proximal de la arteria oftálmica, y un relleno muy débil de la porción orbitaria distal. La paciente se fue recuperando progresivamente del déficit y 9 meses después de la cirugía es capaz de contar dedos. La angiografía actual demuestra un relleno de todas las porciones de la arteria oftálmica, con ausencia de circulación colateral, y exclusión del aneurisma. La manipulación quirúrgica parece haber inducido vasoespasmo o trombosis de la arteria oftálmica. La regresión del vasoespasmo o la recanalización secundaria del trombo sin desarrollo de circulación colateral pueden justificar la mejoría gradual de la visión. Hay un riesgo de amaurosis unilateral asociado al tratamiento quirúrgico de los aneurismas paraclinoideos, aunque existe posibilidad de mejoría en algunos casos.

PALABRAS CLAVE: Arteria oftálmica. Aneurisma. Cirugía. Angiografía. Déficit visual transitorio.

Introduction

Para-clinoid aneurysms are in close proximity to delicate anatomical structures such as the ophthalmic artery and the optic nerve. Hence a risk of visual dysfunction is associated with the surgical exploration of this complex area. The puzzling case of a patient who suffered visual deterioration after clipping of a complex para-clinoid aneurysm is presented. The purpose is to illustrate a reversible phenomenon that occurred and induced a visual deficit. In this context a potential of recovery exists and amaurosis may not necessarily be unremitting. Related anatomical, etiological and patho-physiological aspects are reviewed. Adjuvant techniques that may minimize the risk of visual deficit associated with para-clinoid aneurysm surgery are outlined.

\section{Case report}

A 56-year-old woman complained of headache of sudden onset. Physical examination was unremarkable. CT scanning disclosed spontaneous subarachnoid hemorrhage. 

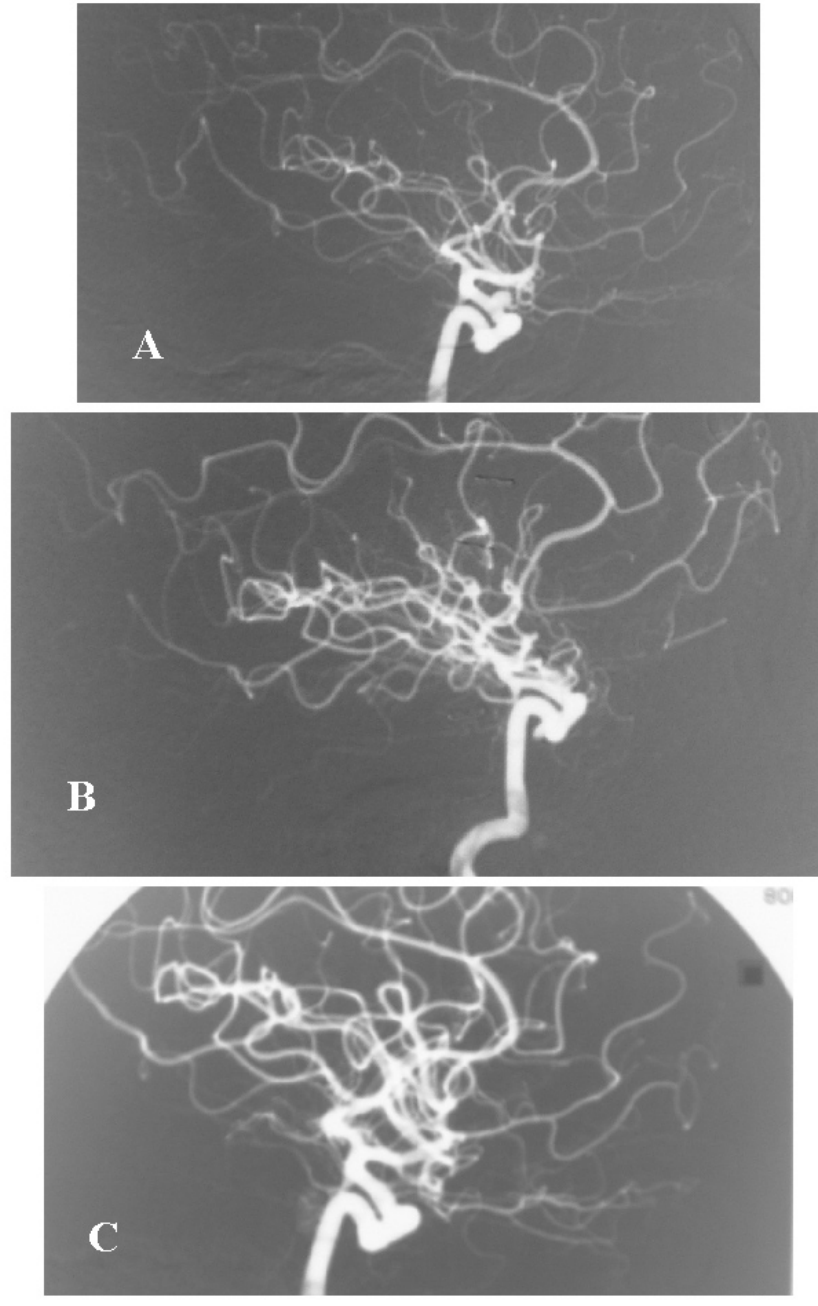

Figure 1. A: pre-operative angiography showing a carotidophthalmic artery aneurysm and patency of the ophthalmic artery. B: angiography one week after surgery confirming exclusion of the aneurysm, no filling of the proximal portion of the ophthalmic artery, and a very faint filling of its distal orbital part. C: 9-month follow-up angiography displaying filling of all the portions of the ophthalmic artery, absence of recruitment of collateral blood supply, and exclusion of the aneurysm as before.

Angiography confirmed the presence of a para-clinoid aneurysm on the right side (figure 1A). The senior author (CA) operated the patient with microsurgical technique. A pterional trans-sylvian approach was employed. The anterior clinoid process was partially drilled to allow for a wide local exposure. An aneurysm of the ophthalmic segment of the internal carotid artery in very close proximity to the origin of the ophthalmic artery was found. The aneurysm was clipped with one straight clip. Great care was taken in confirming the integrity of the origin of the ophthalmic
LEFT

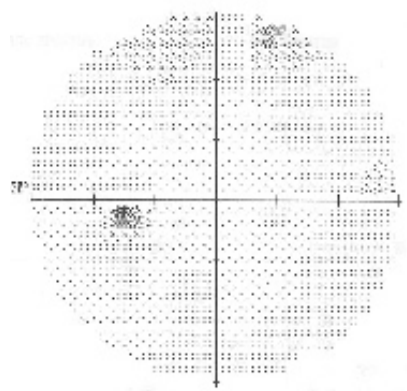

RIGHT

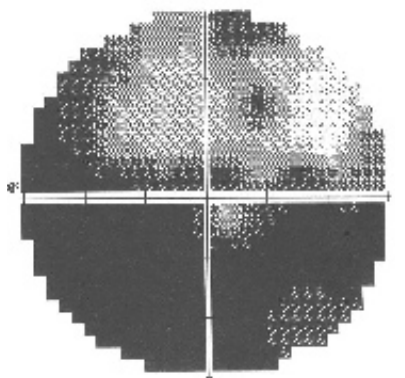

Figure 2. Perimetry nine months after surgery illustrating partial visual field deficit of the right eye, a significant improvement when compared to the immediate post-operative period when there was no light perception.

artery. After placing the clip, intraoperative visual inspection confirmed that this was achieved. The optic nerve was seen intact as well. Severe deterioration of visual acuity of the right eye occurred in the immediate post-operative period, and the patient didn't have light perception on the affected side. An angiography one week after surgery confirmed exclusion of the aneurysm, no filling of the proximal portion of the ophthalmic artery, and a very faint filling of its distal orbital part (figure 1B). Despite this, one month after she had partially recovered from this deficit in a gradual fashion to a point where she could perceive large figures. She was on nimodipine since admission and remained on the drug for a total of three weeks. Intravenous fluids were administered vigorously in the first post-operative week and then tapered without any major hemo-dynamic imbalance. In the 9-month follow-up visit she was capable of counting fingers and perimetry confirmed partial recovery of the visual field deficit (figure 2). Angiography at this time showed filling of the ophthalmic artery, absence of recruitment of collateral blood supply, and the aneurysm remained excluded as before (figure 1C).

\section{Discussion}

\section{Classification of para-clinoid aneurysms}

A proposed classification for para-clinoid aneurysms includes the following categories: (1) carotid cave aneurysms i.e. those arising from the internal carotid artery proximal to the origin of the ophthalmic artery; (2) ophthalmic artery aneurysms i.e those that arise from the ophthalmic artery proper; and (3) ophthalmic segment aneurysms i.e. those arising from the internal carotid artery between the origin of the ophthalmic artery and the origin of the posterior communicating artery. The latter category includes carotid-ophthalmic artery aneurysms i.e. those that have a clear relationship with the origin of the 
ophthalmic artery but do not incorporate the artery ${ }^{5}$. The present case is illustrative of a carotid-ophthalmic artery aneurysm, a rare lesion and somewhat different from the more distal ophthalmic segment aneurysms of the internal carotid artery in terms of feasibility of preservation of the ophthalmic artery.

\section{Etiologies of visual dysfunction}

Trauma of the optic nerve may be implied in the genesis of visual deficit but it is not regarded as a likely explanation in the present case. Abundant saline irrigation was used to avoid heat injury during drilling of the sphenoid wing and clinoid process. The optic nerve was gently manipulated at all times and was left intact.

Placing a clip at the neck of a carotid-ophthalmic artery aneurysm such as this may compromise the blood flow from the internal carotid artery to the ophthalmic artery. Since the central artery of the retina is a branch of the ophthalmic artery, ipsilateral amaurosis can be a consequence of the procedure. Nevertheless, leaving a ruptured aneurysm untreated was felt to imply a dismal prognosis for this patient.

Although not perceived intra-operatively, occlusion of the ophthalmic artery by the tip of the blades of the aneurysm clip was regarded as the most likely explanation for the post-operative amaurosis in view of the absence of filling of the vessel in the first post-operative angiography.

Occlusion of the ophthalmic artery has been associated with permanent blindness in $10 \%$ of the cases ${ }^{3}$. The initial interpretation for the progressive recovery of visual acuity in the following weeks was that recruitment of collateral blood supply was taking place. Anastomoses between the internal and external carotid arteries are possible by means of branches of the ophthalmic artery. Those that may compensate for the occlusion of the ophthalmic artery include the dorsal nasal artery and the lacrimal artery ${ }^{7}$. The former anastomoses with branches of the facial artery. The latter anastomoses by means of a recurrent meningeal branch with branches of the middle meningeal artery. After occlusion of the ophthalmic artery, increase of blood flow through this network may allow for a recovery of perfusion in the central artery of the retina. However, the 9-month angiography confirmed filling of the ophthalmic artery and still exclusion of the aneurysm, thereby not supporting the hypothesis of occlusion of the vessel by the tip of the blades of the clip or clip displacement. Surprisingly, no collateral blood supply was evident.

Vasospasm of the ophthalmic artery has been previously described and implicated in the genesis of visual dysfunction, although out of a surgical context ${ }^{6}$. It may be of a primary or secondary nature. In the present case, vasospasm secondary to surgical manipulation might have affected the ophthalmic artery and explain the transitory arrest of blood flow in the vessel. Thrombosis of the ophthalmic artery and secondary recanalization is a second hypothesis that could account for the phenomenon as well. Nevertheless, the latter is considered less likely in view of the absence of development of collateral blood supply.

\section{Adjuvant techniques that may minimize the risk of visual deficit}

Preoperative temporary balloon occlusion of the ophthalmic and the internal carotid arteries can be employed to evaluate the adequacy of collateral flow and possible impairment of vision ${ }^{9}$. Intra-operative awakening for vision examination during ophthalmic artery aneurysm clipping has been reported, and permitted immediate confirmation of gross preservation of visual acuity after exclusion of the aneurysm and the ophthalmic artery ${ }^{2}$. However, both techniques aren't always readily available and have been used essentially for unruptured aneurysms, contrary to the present case.

Nevertheless, other more widespread adjuvant methods may be of some assistance ${ }^{1,4,8}$. Intra-operative microvascular Doppler sonography can be employed to assess vessel patency, and technical refinements have been introduced that allow for the measurement of blood flow. Also, indocyanine green video angiography allows for the intra-operative assessment of blood flow in vessels visible in the surgical microscope field. However the location in question is of difficult access, and normal and pathological anatomy may not permit a detailed evaluation of all the necessary vessels. Monitoring of visual evoked potentials can be employed during surgery in this area insert; their loss can signal a compromise of visual function. However, influence of the depth of anesthesia should be taken into account when interpreting the results.

\section{Final remarks}

When dealing with paraclinoid aneurysms, impairment of visual acuity on the side of the lesion caused by a compromise of blood flow in the ophthalmic artery is a possible sequel that should be duly appraised. Nevertheless, this severe deficit may be of a transitory nature if vasospasm or thrombosis of the ophthalmic artery are the etiologies involved. Use of adjuvant techniques that may minimize the risk of visual deficit should be considered, and issues related to the added time, cost, risk for the patient, logistics and labor should be weighted and balanced with the benefits that they may bring. 


\section{References}

1. Amin-Hanjani, S., Meglio, G., Gatto, R., Bauer, A., Charbel, F.T.: The utility of intraoperative blood flow measurement during aneurysm surgery using an ultrasonic perivascular flow probe. Neurosurgery 2008; 62: 13461353.

2. Chen, P., Dunn, I.F., Aglio, L.S., Day, A.L., Frerichs, K.U., Friedlander, R.M.: Intraoperative awakening for vision examination during ophthalmic artery aneurysm clipping: technical case report. Neurosurgery 2005; 56: E440.

3. Dehdashti, A.R., Safran, A.B., Martin J.B., Rufenacht, D.A., De Tribolet, N.: Intraorbital ophthalmic artery aneurysm associated with basilar tip saccular aneurysm. Neuroradiology 2002; 44: 600-603.

4. Goto, T., Tanaka, Y., Kodama, K., Kusano, Y., Sakai, K., Hongo, K.: Loss of visual evoked potential following temporary occlusion of the superior hypophyseal artery during aneurysm clip placement surgery. Case report. J. Neurosurg. 2007; 107: 865-867.

5. Kyoshima, K., Kobayashi, S., Orz, Y.I.: Ophthalmic aneurysms. In: Kaye, A.H., Black, P.M., eds. Operative Neurosurgery. London; Churchill Livingstone, 2000; pp. 973984.

6. Mosso, M., Jung, H.H., Baumgartner, R.W.: Recurrent spontaneous vasospasm of cervical carotid, ophthalmic and retinal arteries causing repeated retinal infarcts: a case report. Cerebrovasc Dis 2007; 24: 381-384.

7. O'Rahilly, R.: Gardner Gray O'Rahilly Anatomy. $5^{\text {th }}$ ed. Philadelphia; Saunders, 1986: p.610.

8. Raabe, A., Nakaji, P., Beck, J., Kim, L.J., Hsu, F.P., Kamerman, J.D., Seifert, V., Spetzler, R.F.: Prospective evaluation of surgical microscope-integrated intraoperative near-infrared indocyanine green videoangiography during aneurysm surgery. J. Neurosurg 2005; 103: 982-989.

9. Shaibani, A., Khawar, S., Bendok, B., Walker, M., Russell, E.J., Batjer, H.H.: Temporary balloon occlusion to test adequacy of collateral flow to the retina and tolerance for endovascular aneurysmal coiling. AJNR Am J Neuroradiol 2004; 25: 1384-1386.

Mascarenhas, L.; Ribeiro, M.; Guimaraes, S.; Rocha, J.; Alegria, C.: Unexpected angiographic and visual findings after clipping of a carotid-ophthalmic aneurysm. Neurocirugía 2010; 21: 46-49.

Correspondence: Dr. Lino Mascarenhas. Serviço de Neurocirurgia. Hospital de São Marcos. Apartado 2242. 4701-965 Braga. Portugal.

Email: linomasc@gmail.com 